\title{
DISTRIBUTION OF FAT MASS IN YOUNG TYPE 1 DIABETIC PATIENTS
}

\section{Y.V. Dydyshko, A.P. Shepelkevich}

Department of Endocrinology of the Belarusian state medical university, Minsk, Belarus

\section{OBJECTIVES}

There is convincing evidence that the increasing of visceral fat is a risk factor for vascular disease. Type 1 diabetes mellitus (T1DM) is characterized by the development of micro-, and later, and macrovascular complications

The aim of the study was to examine features of body composition fat distribution parameters in T1DM patients.

The research involved:

$\checkmark$ Anthropometry of patients

$\checkmark$ General clinic examination

$\checkmark$ Dual energy X-ray absorptiometry (Body composition program)

$\checkmark$ Fat mass distribution research was based on Total Body, Android, Gynoid, A/G Ratio, Trunk/Total, Legs/Total (Arms+Legs)/Trunk parameters.

\section{METHODS}

96 patients with T1DM (59 women, 37 males) and 54 ( 30 women, 24 men) controls matched for age, sex and body mass index were examined (Table1)

Table 1 - Clinical and laboratory characteristics of the examined patients with T1DM and control subjects

\begin{tabular}{|l|c|c|c|}
\hline Characteristic & T1DM patients & Controls & $p$ \\
\hline Sex, w:m & $59: 37(61 \%: 39 \%)$ & $30: 24(56: 44 \%)$ & \\
\hline Age $(\mathrm{yrs})$ & $31,76 \pm 8,21$ & $29,90 \pm 6,43$ & 0,28 \\
\hline Height, sm & $166,31 \pm 7,04$ & $167,08 \pm 5,03$ & 0,60 \\
\hline Weight, kg & $64,13 \pm 9,85$ & $62,37 \pm 9,05$ & 0,41 \\
\hline BMI (kg/m2) & $23,14 \pm 2,88$ & $22,31 \pm 2,90$ & 0,21 \\
\hline Waist, sm & $76,29 \pm 5,72$ & $71,00 \pm 5,83$ & 0,08 \\
\hline Disease duration (yrs) & $13,45 \pm 7,52$ & & \\
\hline Age of T1D onset (yrs) & $18,50 \pm 8,09$ & & \\
\hline HBA1c & $8,57 \pm 1,22$ & $5,02 \pm 0,27$ & $<, 001$ \\
\hline
\end{tabular}

- Data are expressed as mean SD and \%

\section{RESULTS}

$\checkmark$ Lean mass parameters in T1DM males and women compared with controls were:

\begin{tabular}{|c|c|c|c|c|c|c|}
\hline \multirow[t]{2}{*}{ Region } & \multicolumn{2}{|c|}{ women } & \multirow[t]{2}{*}{$p$} & \multicolumn{2}{|c|}{ men } & \multirow[t]{2}{*}{$p$} \\
\hline & $\begin{array}{c}\text { T1DM } \\
\text { patients }\end{array}$ & Controls & & T1DM patients & Controls & \\
\hline Android fat,\% & $32,29 \pm 8,44$ & $32,37 \pm 10,81$ & 0,97 & $27,41 \pm 11,43$ & $28,8 \pm 9,67$ & 0,627 \\
\hline Gynoid fat,\% & $41,72 \pm 6,63$ & $41,36 \pm 7,16$ & 0,81 & $28,06 \pm 7,15$ & $26,74 \pm 7,74$ & 0,506 \\
\hline A/G Ratio & $0,76 \pm 0,14$ & $0,45 \pm 0,05$ & 0,97 & $0,95 \pm 0,24$ & $1,06 \pm 0,15$ & 0,048 \\
\hline Total Body,\% & $33,25 \pm 6,7$ & $32,3 \pm 7,59$ & 0,102 & $23,02 \pm 7,9$ & $22,55 \pm 7,5$ & 0,551 \\
\hline Trunk/Total & $0,44 \pm 0,048$ & $0,45 \pm 0,056$ & 0,611 & $0,516 \pm 0,07$ & $0,54 \pm 0,034$ & 0,094 \\
\hline Legs/Total & $0,412 \pm 0,05$ & $0,415 \pm 0,054$ & 0,812 & $0,35 \pm 0,06$ & $0,32 \pm 0,032$ & 0,093 \\
\hline $\begin{array}{l}(\text { Arms }+ \text { Legs }) / T \\
\text { runk }\end{array}$ & $1,18 \pm 0,25$ & $1,17 \pm 0,3$ & 0,837 & $0,9 \pm 0,28$ & $0,77 \pm 0,105$ & 0,034 \\
\hline
\end{tabular}

Gynoid (peripheric) fat distribution was positively correlated with the age of T1DM males ( $r=0.19$; $p=0,018)$, however no correlation was found with the duration of the disease, level $\mathrm{HbA1c}$, the total daily insulin dose.

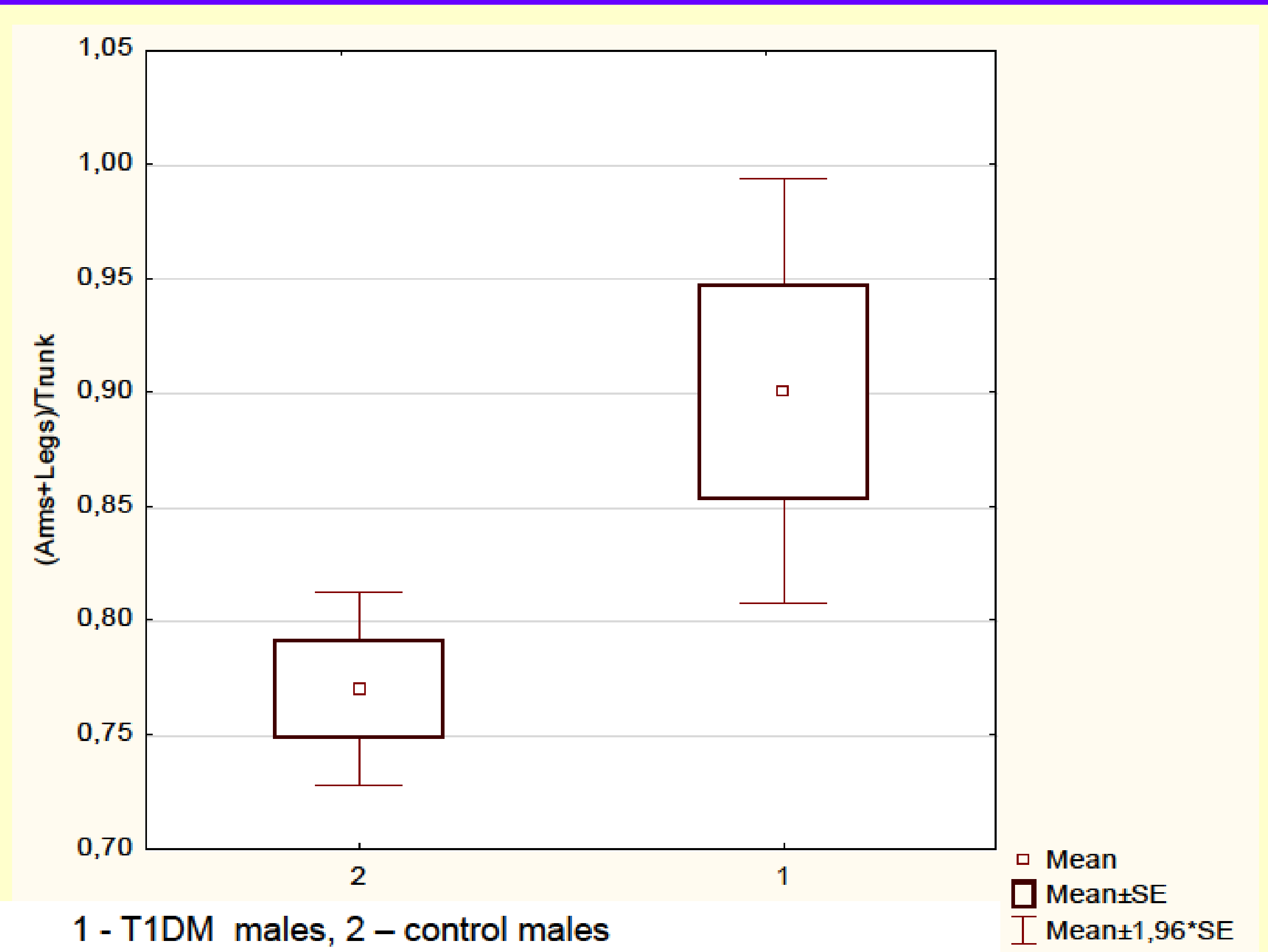

\section{CONCLUSIONS}

The peripheral type of fat mass distribution is dominated at T1DM males compared with healthy males, while there were no differences in the distribution of adipose tissue among the investigated women.

The obtained data indicate gender differences in the distribution of fat mass in T1DM patients. 